\title{
The effect of co-expression costimulatory molecule CD80 on uptake of antigen peptide-MHC class I-GFP complex by specific $T$ cells
}

\author{
XIA LIU* , LEILEI ZHANG* ${ }^{*}$ XINGQIAN ZHANG, HAI YU, XIAOPING ZHAO, \\ JIAN LU, GUANXIANG QIAN and SHENGFANG GE \\ Research Center for Human Gene Therapy, Department of Biochemistry and Molecular Biology, \\ School of Medicine, Shanghai Jiao Tong University, Shanghai, P.R. China
}

Received January 2, 2007; Accepted February 22, 2007

\begin{abstract}
CD80, a costimulatory molecule, plays an important role in eliciting antitumor immunity. Without costimulation, recognition of antigens by $\mathrm{T}$ cells may not cause a response, even if tumor cells express MHC class I molecules and specific antigens. On the basis of the recombinant GFP-tagged $\mathrm{K}^{\mathrm{b}}$ molecule, we constructed a co-expression vector of CD80 and GFP-tagged $\mathrm{K}^{\mathrm{b}}$ molecules. The recombinant fusion was transfected into mouse melanoma B16 cells by electroporation; positive cells were obtained by G418 screening. Highly expressing monoclonal cells, irradiated by ${ }^{137} \mathrm{Cs}$, were used to immunize mice to obtain specific $\mathrm{T}$ cells, which were then cultivated with tumor cells in vitro and examined with a laser confocal microscope. The evident and intense uptake of the antigen peptide-MHC class I-GFP complex by specific $\mathrm{T}$ cells was visualized from the culture of B16/CD80-K $\mathrm{K}^{\mathrm{b}}$-GFP and $\mathrm{T}$ cells. However, little uptake was observed from the culture of $\mathrm{B} 16 / \mathrm{K}^{\mathrm{b}}-\mathrm{GFP}$ and $\mathrm{T}$ cells. These results show that co-expression of CD80 molecules with $\mathrm{K}^{\mathrm{b}}$, an MHC class I molecule, on the surface of B16 tumor cells can enhance the response of specific $\mathrm{T}$ cells and thus increase the uptake of
\end{abstract}

Correspondence to: Dr Shengfang Ge or Professor Guanxiang Qian, Research Center for Human Gene Therapy, Department of Biochemistry and Molecular Biology, School of Medicine, Shanghai Jiao Tong University, 280 Chongqing Road South, Shanghai 200025, P.R. China

E-mail: geshengfang@sjtu.edu.cn qiangx@shsmu.edu.cn

${ }^{*}$ Contributed equally

Abbreviations: GFP, green fluorescent protein; MHC, major histocompatibility complex; PCR, polymerase chain reaction; FITC, fluorescein-isothiocyanate; PE, phycoerythrin; CMV, cytomegalovirus; RT-PCR, reverse transcription PCR; GAPDH, glyceraldehyde3-phosphate dehydrogenase; CTL, cytotoxic T lymphocyte

Key words: CD80, MHC class I, T cell activation, co-expression, tumor antigen peptides the antigen peptide-MHC class I-GFP complex. The absorbed green fluorescence was concentrated mainly on the $\mathrm{T}$ cell surface, and this result might pave the way to eluting specific antigen peptides directly from $\mathrm{T}$ cells to find and isolate novel tumor-specific antigen peptides.

\section{Introduction}

T cell-mediated cellular immunity is the main source of antitumor activity. The signal following detection of antigenmajor histocompatibility complexes (MHCs) by the antigen receptor is not sufficient to elicit an immune response. Optimal activation of $\mathrm{T}$ cells requires two distinct signals. The first signal is mediated by MHC-restricted, antigen-specific triggering of the T-cell receptor (TCR) complex. The second signal comes from an antigen-independent mechanism, and is termed costimulation. The second signal is delivered by costimulatory molecules on the antigen-presenting cells (APCs) through their counter-receptors on the T lymphocytes. Without costimulation, exposure of $\mathrm{T}$ cells to an antigen may not cause a response (1-3).

There are several molecules that can provide costimulation. Particular interest has been given recently to B7 (B7.1 or B7.2), which is the natural ligand for the CD28 and cytotoxic $\mathrm{T}$ lymphocyte (CTLA-4) counter receptors on T cells, and it is one of the most pivotal costimulatory molecules for inducing functional T-cell responses. CD28 is constitutively expressed on T cells; CTLA-4 is induced and expressed only on activated T cells. When CD28 binds CD80 (B7.1), T cells are stimulated to differentiate and proliferate. CTLA-4 has a higher affinity for CD80 and appears to deliver a negative signal to $\mathrm{T}$ cells. Stimulation of $\mathrm{T}$ cells in the absence of CD28-CD80(B7.1)/CD86(B7.2)-mediated costimulation results in impaired proliferation, reduced production of cytokine, and altered Th1/Th2 balance (4). The CD80 (B7.1) molecule was first identified as a member of the B7 family, and is expressed mostly on dendritic cells, activated macrophages, and activated B cells. It plays an important role in the activation of $\mathrm{T}$ cells, because data show that tumor cells can induce antigenspecific tolerance and make the tumor cell immune anergy on the basis of MHC class I-restricted antigen presentation with lack of expression of costimulatory ligands. Other investigators have shown that tumor cells genetically engineered to express 
$\mathrm{CD} 80$ induce $\mathrm{CD} 8^{+}$cytotoxic $\mathrm{T}$ cells that provide protective immunity by lysing CD80- tumor cells (5-7).

Tumor cells seldom express CD80 molecules, except for those derived from B cells. One of the important mechanisms by which tumor cells escape immunity killing is that they do not, or only weakly, express CD80 molecules (8). The application of molecular biology techniques to transfect costimulatory molecules into tumor cells can lead to the strengthening of the effects of $\mathrm{T}$ cells, including cell proliferation, secretion of cytokine and CTL activity (9-11). Little uptake was observed from the culture of $\mathrm{B} 16 / \mathrm{K}^{\mathrm{b}}$-green fluorescent protein (GFP) and $\mathrm{T}$ cells when the recombinant GFP-tagged $\mathrm{K}^{\mathrm{b}}$ molecule was transfected into the mouse melanoma B16 cells lacking the expression of MHC class I molecules $(12,13)$. Thus, we constructed a co-expression vector containing CD80 and GFP-tagged $\mathrm{K}^{\mathrm{b}}$ molecules to enhance the expression of the costimulatory CD80 molecule and provide a foundation for the further activation of the antigen-specific $\mathrm{T}$ cells and induction of the effective anti-tumor immunity by enhancing the tumor cellular immunity responses through the synergetic effect of MHC class I molecules and costimulatory molecule.

\section{Materials and methods}

Experimental animals, cell lines and plasmids. Female C57BL/6 mice, 6-8 weeks old, were treated according to the NIH Guidelines for Animal Care in the Experimental Animal Center of Shanghai Jiao Tong University School of Medicine. Mouse melanoma B16 cells were obtained from ATCC, maintained in RPMI-1640 medium supplemented with $10 \%$ bovine calf serum and cultured at $37^{\circ} \mathrm{C}$ in a $5 \% \mathrm{CO}_{2}$ incubator. Escherichia coli strain JM109 was bought from ATCC, eukaryotic expression vector pGL3/CD80, and pcDNA3.0/mK $\mathrm{m}^{\mathrm{b}}$-GFP were constructed and conserved by our laboratory.

Reagents. The following materials were obtained: RPMI-1640 medium and G418 (Invitrogen), bovine calf serum (PAA Laboratory $\mathrm{GmbH}$ Co.), plasmid purification kit MIDIPREP (Gibco), fetal calf serum (Hyclone), TRIzol ${ }^{\circledR}$ total RNA purification kit and reverse transcription reaction agent (Invitrogen), polymerase chain reaction (PCR) agent and restriction endonuclease (Takara), fluorescein isothiocyanate (FITC)-anti-mouse CD80 antibody, anti-mouse H-2K $\mathrm{K}^{\mathrm{b}}$ antibody and PE-anti-mouse TCR- $\beta$ monoclonal antibody (eBioScience), mononuclear cells isolation solution $(1.077 \mathrm{~g} /$ $\mathrm{cm}^{3}$; Lymphoprep ${ }^{\mathrm{TM}}$ (Axis-shield polAS), IsoCell ${ }^{\mathrm{TM}}$ mouse $\mathrm{T}$ cell isolation kit (Pierce), Xinluoer recombinant human interleukin-2 for injection (Shanghai New Bio-Tech Ltd.), FITC-anti-mouse CD8 antibody (Proimmune), and PE-antimouse CD8 antibody (Pharmingen).

Construction of the co-expression vector of $p G L 3 / C D 80-m K^{b_{-}}$ GFP. Vectors pcDNA3.0/mK ${ }^{\mathrm{b}}-\mathrm{GFP}$ and $\mathrm{pGL} 3 / \mathrm{CD} 80$ were digested with $B g l I I$ and $S m a I$ individually, and then $\mathrm{mK}^{\mathrm{b}}$-GFP was inserted into pGL3/CD80 to obtain the co-expression vector $\mathrm{pGL} 3 / \mathrm{CD} 80-\mathrm{mK}^{\mathrm{b}}-\mathrm{GFP}$.

$\mathrm{mK}^{\mathrm{b}}$-GFP was driven by the cytomegalovirus (CMV) promoter and CD80 was driven by the SV40 promoter (plasmid

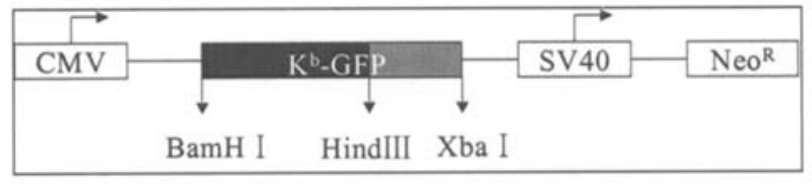

(A)

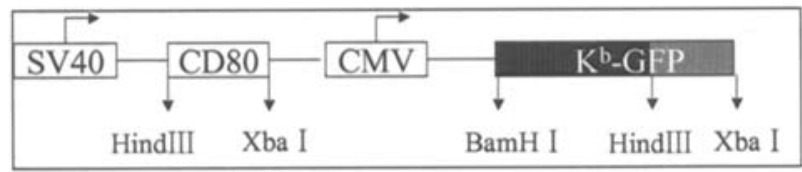

(B)

Figure 1. The structure of recombinant vectors. The map of the recombinant vector pcDNA3.0/ $\mathrm{mK}^{\mathrm{b}}-\mathrm{GFP}: \mathrm{K}^{\mathrm{b}}-\mathrm{GFP}$ is a fusion gene, its transcription is initiated by the upstream promoter CMV, and its downstream is the neo ${ }^{\mathrm{R}}$ gene sequence whose transcription is initiated by SV40. The map of the recombinant vector pGL3/CD80-mK ${ }^{\mathrm{b}}$-GFP: SV40 initiates transcription of the CD80 gene, CMV initiates the transcription of the fusion gene $\mathrm{K}^{\mathrm{b}}-\mathrm{GFP}$. They were expressed from the same transcript and became the co-expression vector $\mathrm{pGL} 3 / \mathrm{CD} 80-\mathrm{mK}^{\mathrm{b}}-\mathrm{GFP}$.

maps, Fig. 1). The preparation of plasmid followed the instructions supplied with the plasmid purification kit (Gibco).

Electroporation transfection of melanoma B16 cells. B16 cells were transfected into pGL3/CD80-mK ${ }^{\mathrm{b}}-\mathrm{GFP}$ and pcDNA3.0/ $\mathrm{mK}^{\mathrm{b}}$-GFP, which were digested with $B g l I I$, at $280 \mathrm{mV}, 960 \mu \mathrm{F}$ (14). pGL3/CD80-mK ${ }^{\mathrm{b}}$-GFP was transfected with $1 / 50$ of plasmid pSV40/neo. After electroporation transfection for 48 h, RPMI-1640 medium containing G418 (0.5 mg/ml) was added and the medium was changed until recombinant cells were produced in good condition. Normally, some clones were seen after screening for a week, and a stable transfection cell line was constructed after 3 weeks, then the monoclonal cell line was cultured by limiting dilution techniques.

Reverse transcription (RT)-PCR. For the reverse transcription system $(20 \mu \mathrm{l}), 5 \mu \mathrm{g}$ of total RNA, $2 \mu \mathrm{l}$ of random primer, and $1 \mu \mathrm{l}$ of $10 \mathrm{mM} \mathrm{dNTP}$ were added to $6 \mu \mathrm{l}$ of diethyl pyrocarbonate-treated water. After mixing, they were denatured at $65^{\circ} \mathrm{C}$ for $5 \mathrm{~min}$ followed by immediate immersion in an ice-water bath. Then $4 \mu 1$ of $5 \mathrm{X}$ reaction buffer, $2 \mu 1$ of $0.1 \mathrm{M}$ DTT, and $1 \mu \mathrm{l}$ of RNaseOUT were added and mixed at $37^{\circ} \mathrm{C}$ for $2 \mathrm{~min}$. Finally, M-MLV reverse transcriptase was added, and mixed at $25^{\circ} \mathrm{C}$ for $10 \mathrm{~min}$, then at $70^{\circ} \mathrm{C}$ for $15 \mathrm{~min}$.

Amplification of target genes. For CD80, the upstream primer was 5'-TCC CAA GCT TCA AAG CAT CTG AAA CCA TGG CT-3', and the downstream primer was 5'-TGC TCT AGA CTA AAG GAA GAC GGT C-3'; for GFP, the upstream primer was 5'-TAG AAT TCA TGG TGA GCA AGG CGA GGA GCT G-3', and the downstream primer was 5'-GAT CTA GAG TCG CGG CCG CTT TAC TTG TAC AG-3'.

For the PCR reaction system $(50 \mu 1), 10 \mathrm{X}$ reaction buffer, $1 \mu \mathrm{l}$ of $10 \mathrm{mM}$ dNTP, $2 \mu \mathrm{l}$ of RT reaction product, and $39.5 \mu \mathrm{l}$ of double-distilled water were used. The mixture was denatured by heating at $94^{\circ} \mathrm{C}$ for 5 min followed by immediate immersion in an ice-water bath, then $0.5 \mu 1$ of Taq DNA polymerase ( $5 \mathrm{U} /$ $\mu 1)$ was added. 
The PCR cycle was as follows: GFP, $94^{\circ} \mathrm{C}$ for $40 \mathrm{sec}$, $58^{\circ} \mathrm{C}$ for $1 \mathrm{~min}, 72^{\circ} \mathrm{C}$ for $1 \mathrm{~min}$; $\mathrm{CD} 80,94^{\circ} \mathrm{C}$ for $1 \mathrm{~min}, 60^{\circ} \mathrm{C}$ for $1 \mathrm{~min}, 72^{\circ} \mathrm{C}$ for $1 \mathrm{~min}$; repeated 30 times, and then extended at $72^{\circ} \mathrm{C}$ for another $10 \mathrm{~min}$.

After the reaction, $5 \mu 1$ of PCR product was extracted and run on $1.2 \%(\mathrm{w} / \mathrm{v})$ agarose gel at $3 \mathrm{~V} / \mathrm{cm}$. The gel was scanned under a UV lamp, and glyceraldehyde-3-phosphate dehydrogenase (GAPDH) was used as a control.

Flow cytometry. The detection of GFP in fusion protein was as follows: $1 \times 10^{6}$ target cells were collected per sample, washed twice with PBS, centrifuged at $1000 \mathrm{rpm}$ for $5 \mathrm{~min}$, and then suspended in $200 \mu \mathrm{l}$ of PBS. The sample of B16 cells was used as a GFP-negative control.

The detection of CD80 was as follows: $1 \times 10^{6}$ target cells were collected per sample, washed with cleaning solution [PBS containing $0.1 \%(\mathrm{w} / \mathrm{v})$ sodium azide and $0.1 \%(\mathrm{w} / \mathrm{v})$ bovine serum albumin], and centrifuged at $1000 \mathrm{rpm}$ for $5 \mathrm{~min}$. Then $100 \mu 1$ of FITC-anti-mouse CD80 antibody (diluted $1 / 100$ ) was added and the mixture was cooled in an ice-water bath in the dark for $30 \mathrm{~min}$, washed twice with cleaning solution and then $200 \mu 1$ of PBS fixative containing $2.5 \%$ $(\mathrm{v} / \mathrm{v})$ formaldehyde was added.

The detection of $\mathrm{CD}^{+} \mathrm{T}$ cells was as follows: the isolated mononuclear cells $\left(5 \times 10^{5}\right.$ cells $)$ were taken from the spleens of immunized mice, washed twice with cleaning solution and resuspended in $100 \mu \mathrm{l}$ of cleaning solution. Then $1 \mu \mathrm{l}$ of FITC-anti-mouse CD8 antibody was added and the sample was kept on ice for $30 \mathrm{~min}$, before being washed twice with cleaning solution and resuspended in $200 \mu 1$ of PBS fixative containing $1 \%(\mathrm{v} / \mathrm{v})$ fetal calf serum and $2.5 \%(\mathrm{v} / \mathrm{v})$ formaldehyde.

Immunization of mice with gene-modified B16 cells. Female C57BL/6 mice, 6-8 week old, were divided into three groups of five mice: group 1, hypodermic injection of monoclonal B16/CD80-K ${ }^{\mathrm{b}-G F P}$ cells $\left(1 \times 10^{6}\right.$ cells/per mouse) irradiated with ${ }^{137} \mathrm{Cs}$; group 2 , hypodermic injection of monoclonal $\mathrm{B} 16 / \mathrm{K}^{\mathrm{b}}$-GFP cells $\left(1 \times 10^{6}\right.$ cells/per mouse $)$ irradiated with ${ }^{137} \mathrm{Cs}$; group 3, hypodermic injection of monoclonal B16 cells $\left(1 \times 10^{6}\right.$ cells/per mouse) irradiated with ${ }^{137} \mathrm{Cs}$. Mice were immunized by hypodermic injection and again after 1 week (15).

Preparation of mononuclear cells and isolation of $T$ cells. C57BL/6 mice were sacrificed 14 days after the last immunization, the spleens were removed and ground into a cell suspension, which was added to $3 \mathrm{ml}$ of mononuclear cell separation liquid and centrifuged at $1500 \mathrm{rpm}$ for $20 \mathrm{~min}$ at $20^{\circ} \mathrm{C}$. Interface cells were removed, washed twice with PBS, placed into a 6-well plate and cultured with RPMI-1640 medium containing $10 \%$ bovine calf serum. Recombinant human IL-2 was added to a final concentration of $500 \mathrm{IU} / \mathrm{ml}$ to support the growth of lymphocytes. Mononuclear cells were incubated at $37^{\circ} \mathrm{C}$, in a $5 \% \mathrm{CO}_{2}$ atmosphere, for $48 \mathrm{~h}$, and then $\mathrm{T}$ cells were isolated and enriched according to the instructions supplied with the $\mathrm{T}$ cell isolation kit. Before culturing the tumor cells with specific $\mathrm{T}$ cells, the $\mathrm{T}$ cells were cultured in the medium without IL-2 for $48 \mathrm{~h}$ to keep them synchronized.

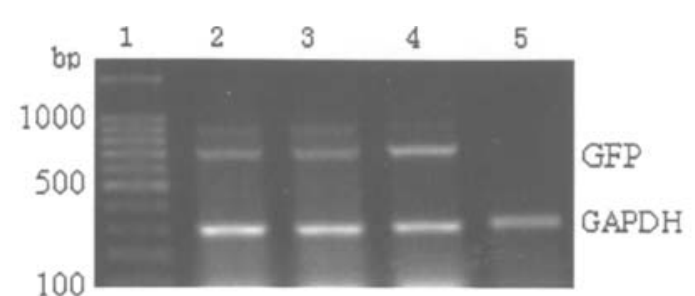

(A)

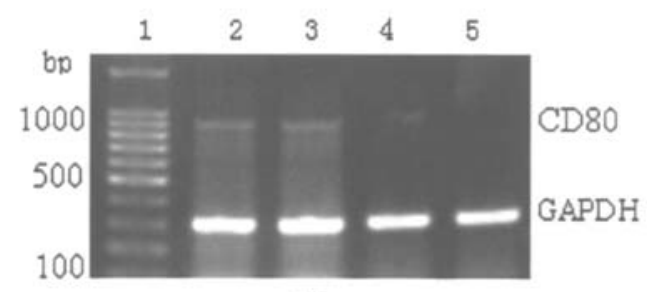

(B)

Figure 2. RT-PCR analysis. Highly expressed monoclonal cell lines were screened by the limiting dilution technique. The expression of GFP and CD80 was analyzed by RT-PCR, and GAPDH (300 bp) was used as the control. (A) The expression of GFP of the monoclonal cell. (B) The expression of CD80 of the monoclonal cell. Lane 1, 100-bp marker; lane 2, CD80-10F; lane 3, CD80-10H; lane 4, $\mathrm{K}^{\mathrm{b}}-11 \mathrm{~B}$; lane 5, B16 cells.

Observation using laser scanning confocal fluorescence microscopy. Direct observation of the uptake of the antigen peptide-MHC class I-GFP complex by T cells was as follows: sterilized clean glass coverslips were put into a 6-well plate and the highly expressed monoclonal cell lines B16/K $\mathrm{K}_{-}^{\mathrm{G}} \mathrm{GFP}$ and B16/CD80-K $\mathrm{K}^{\mathrm{b}}-\mathrm{GFP}$ were plated on them. When cells covered approximately $80 \%$ of the growth surface, the culture medium was removed. Isolated $\mathrm{T}$ cells were dropped onto the glass coverslips. After $1 \mathrm{~h}$ at $37^{\circ} \mathrm{C}$, the green fluorescence of GFP was observed directly with a laser scanning confocal fluorescence microscope at an excitation wavelength of $488 \mathrm{~nm}$ and an emission wavelength of $512 \mathrm{~nm}$, with a focusing aperture of $2 \mu \mathrm{m}$ (resolution 1024x1024 pixels).

Dual-channel fluorescence analysis was as follows: B16 cells, B16/K $\mathrm{K}^{\mathrm{b}}-\mathrm{GFP}$ cells and B16/CD80-K $\mathrm{K}^{\mathrm{b}}-\mathrm{GFP}$ cells were cultured with $\mathrm{T}$ cells individually as described above. After incubation at $37^{\circ} \mathrm{C}$ for $1 \mathrm{~h}$, T cells were tagged with PE-antimouse TCR- $\beta$ monoclonal antibody and kept on ice for $30 \mathrm{~min}$ in the dark. The cells were washed twice with cleaning solution and resuspended in $200 \mu \mathrm{l}$ of PBS fixative solution containing $1 \%$ fetal calf serum and $2.5 \%$ formaldehyde. Finally, the suspension was dropped onto the glass coverslips covered with tumor cells, and observed with a laser scanning confocal fluorescence microscope at an excitation wavelength of $488 \mathrm{~nm}$ and an emission wavelength of $512 \mathrm{~nm}$ to observe green fluorescence, or at $570 \mathrm{~nm}$ to observe red fluorescence.

\section{Results}

Identification of monoclonal cell line by RT-PCR. Highly expressed monoclonal cell lines were screened by the limiting dilution technique. B16/K $\mathrm{K}^{\mathrm{b}}$-GFP monoclonal cells were named as $\mathrm{K}^{\mathrm{b}}-11 \mathrm{~B}$ and $\mathrm{K}^{\mathrm{b}}-9 \mathrm{C}$, while B16/CD80-K $\mathrm{K}^{\mathrm{b}}-\mathrm{GFP}$ monoclonal cells were named as CD80-10F and CD80-10H. The results of the RT-PCR test showed that GFP (700 bp) (Fig. 2A) of the monoclonal cell line B16/K $\mathrm{K}^{\mathrm{b}}$-GFP and CD80 (900 bp) (Fig. 2B) 


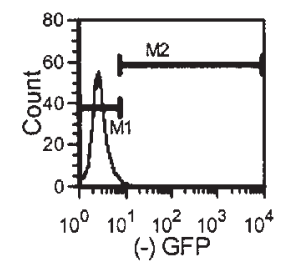

B16

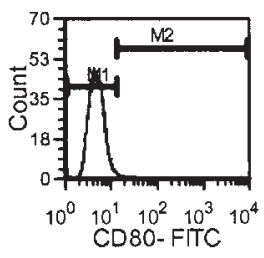

B16

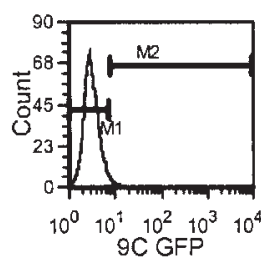

B16/K $K^{\mathrm{b}}-\mathrm{GFP}-9 \mathrm{C}$

(A)

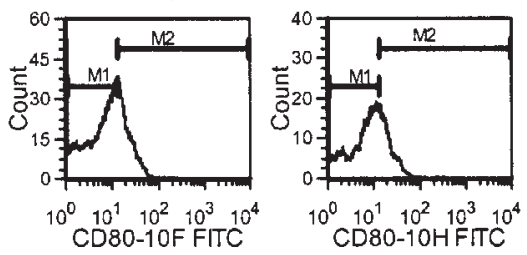

B16/CD $80-K^{\text {b }}-$ GFP-10F $\quad$ B16/CD80-K - GFP-10H
Figure 3. FACS analysis of the expression of GFP and CD80 on the monoclonal cell surface. (A) The expression of GFP of B16/K $\mathrm{K}_{-}-\mathrm{GFP}$ monoclonal cells. A total of $1 \times 10^{6}$ cells of each monoclonal cell line were collected and B16 cells were chosen as the GFP-negative control. (B) The expression of CD80 of B16/CD80-K ${ }^{\mathrm{b}}-\mathrm{GFP}$ monoclonal cells. A total of $1 \times 10^{6}$ cells of each monoclonal cell line were collected and tagged with FITC-anti-mouse CD80 antibody. The B16 cells were used as the FITC-CD80-negative control.

of the monoclonal cell line B16/CD80-K ${ }^{\mathrm{b}}-\mathrm{GFP}$ were expressed stably.

FACS analysis of monoclonal cell lines. The expression of the GFP fusion protein of $\mathrm{K}^{\mathrm{b}}-11 \mathrm{~B}$ and $\mathrm{K}^{\mathrm{b}}-9 \mathrm{C}$ was 11.59 and $4.93 \%$, respectively, as determined by flow cytometry (Fig. 3A). However, the expression of CD80 in cell lines CD80-10F and CD80-10H was 36.44 and $34.15 \%$, respectively (Fig. 3B). On the basis of the above results, we chose the highexpression monoclonal cell lines $\mathrm{K}^{\mathrm{b}}-11 \mathrm{~B}$ and $\mathrm{CD} 80-10 \mathrm{~F}$ for the following experiment. In addition, to further describe the expression of each transfected gene of the monoclonal cell lines we used, we measured the expression of $\mathrm{K}^{\mathrm{b}}$ molecules of the fusion protein using FITC-anti-mouse $\mathrm{H}-2 \mathrm{~K}^{\mathrm{b}}$ antibody. The results showed that the expression of $\mathrm{K}^{\mathrm{b}}$ in cell lines $\mathrm{K}^{\mathrm{b}}-11 \mathrm{~B}$ and CD80-10F was 62.93 and $47.30 \%$, respectively. The coexpression of CD80 in cell line CD80-10F was measured as $40.73 \%$ using the FITC-anti-mouse CD80 antibody (Fig. 4).
FACS analysis of $C D 8^{+} T$ cells of mononuclear cells. To compare the antigen-specific $\mathrm{CD} 8^{+} \mathrm{T}$ cells in the body when mice were immunized with each tumor cell irradiated with isotope, we chose the mononuclear cell that had the most $\mathrm{CD}^{+} \mathrm{T}$ cells according to the number of $\mathrm{CD}^{+} \mathrm{T}$ cells of five mice of each group. Finally, we chose the B16/CD80-K ${ }^{\mathrm{b}}-$ GFP mononuclear cell (16.10\%), the B16/K $\mathrm{K}^{\mathrm{b}}$-GFP mononuclear cell $(16.74 \%)$ and the B16 mononuclear cell (18.33\%), and isolated their $\mathrm{T}$ cells for use in the following experiments (Fig. 5).

Observation of the uptake of the antigen peptide-MHC class I-GFP complex by $T$ cells using laser scanning confocal fluorescence microscopy. The state of gene-modified B16 cells and specific $\mathrm{T}$ cells after they were cultured together for $1 \mathrm{~h}$ was observed using a laser scanning confocal fluorescence microscope. Fig. 6A shows that little uptake of the antigen peptide-MHC class I-GFP complex by specific $\mathrm{T}$ cells was observed from the culturing of $\mathrm{B} 16 / \mathrm{K}^{\mathrm{b}}-\mathrm{GFP}$ with $\mathrm{T}$ cells. However, the evident and intense uptake of the antigen peptideMHC class I-GFP complex by specific $\mathrm{T}$ cells was visualized from the culturing of B16/CD80-K $\mathrm{K}^{\mathrm{b}}$-GFP with T cells. Moreover, the absorbed green fluorescence was concentrated mainly on the $\mathrm{T}$ cell surface (Fig. 6B and C). In a previous version of Fig. 6C, a number of $\mathrm{T}$ cells having taken up the GFP green fluorescent complex were observed. In order to prove that the green fluorescent points are $\mathrm{T}$ cells and not some other components, the cell indicated by the red arrow was further amplified, indicating the integrity of its cell structure. These results show that the co-expression of costimulatory molecule CD80 with $\mathrm{K}^{\mathrm{b}}$, an MHC class I molecule, on the surface of tumor cells can enhance the reaction between $\mathrm{T}$ cells and tumor cells, and increase the uptake of the antigen peptide-MHC class I-GFP complex.

Dual-channel fluorescence analysis of the uptake of the antigen peptide-MHC class I-GFP complex by $T$ cells. T cells were tagged with PE-anti-mouse TCR antibody to prove the uptake of the antigen peptide-MHC class I-GFP complex by T cells. Since GFP and phycoerythrin (PE) use the same excitation wavelength, dual channel technology can be used to observe the green fluorescence of GFP and the red fluorescence of PE. Fig. 6 shows that $\mathrm{T}$ cells exhibited only the red fluorescence of PE when B16 cells were cultured with specific T cells (Fig. 7A). However, when B16/K ${ }^{\mathrm{b}}$-GFP cells were cultured
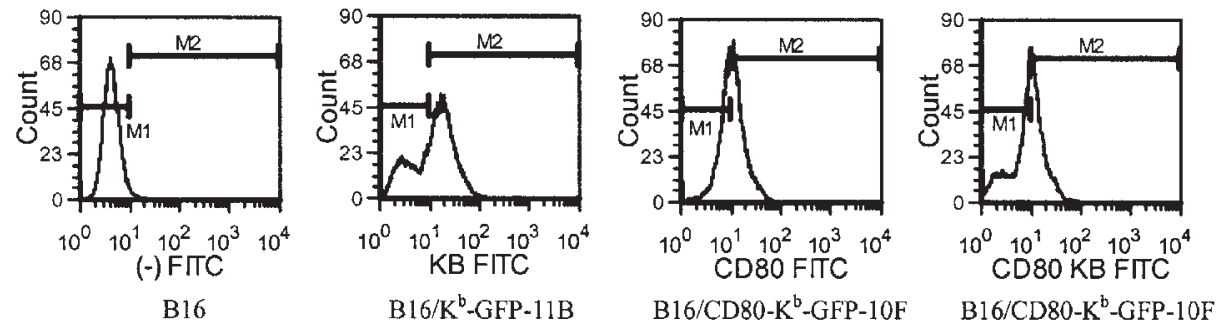

Figure 4. FACS analysis of $\mathrm{K}^{\mathrm{b}}$ expression on the surface of monoclonal cell lines of $\mathrm{K}^{\mathrm{b}}-11 \mathrm{~B}$ and CD80-10F. Among the selected high-expression monoclonal cell lines $\mathrm{K}^{\mathrm{b}}-11 \mathrm{~B}$ and $\mathrm{CD} 80-10 \mathrm{~F}$, we measured expression of the $\mathrm{K}^{\mathrm{b}}$ molecule of the fusion protein using FITC-anti-mouse $\mathrm{H}-2 \mathrm{~K}^{\mathrm{b}}$ antibody. A total of $1 \mathrm{x} 10^{6}$ cells of each monoclonal cell line were collected and tagged with FITC-anti-mouse H-2K $\mathrm{K}^{\mathrm{b}}$ antibody, the B16 cell was used as the GFP-negative control. In addition, cell line CD80-10F was tagged with FITC-anti-mouse CD80 antibody and used to measure the co-expression of CD80. 

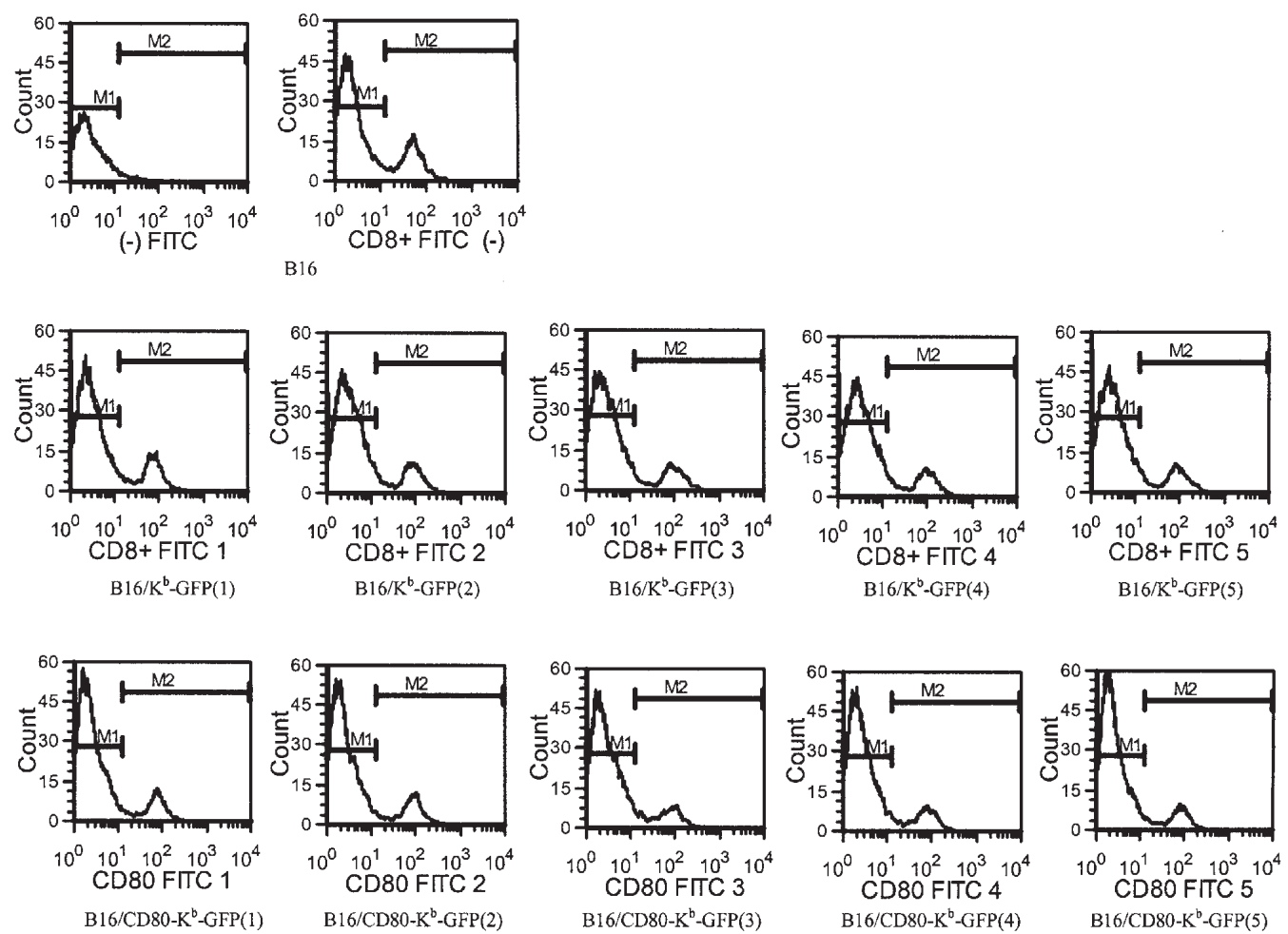

Figure 5. FACS analysis of CD8 ${ }^{+}$- T-cell response elicited by ${ }^{137} \mathrm{Cs}$-irradiated gene-modified B16 cells. Hypodermic injection of monoclonal B16/K ${ }^{\mathrm{b}}$-GFP cells $\left(1 \times 10^{6}\right.$ cells) and B16/CD80-K ${ }^{\mathrm{b}}$-GFP cells ( $1 \times 10^{6}$ cells) irradiated with ${ }^{137} \mathrm{Cs}$, using B16 cells as the control. After 14 days, we sacrificed the mice, removed the spleens and isolated mononuclear cells. Mononuclear cells $\left(5 \times 10^{5}\right.$ cells) were tagged with FITC-anti-mouse CD $8^{+}$antibody and the number of mononuclear CD $8^{+}$ T cells was counted by flow cytometry.

with specific $\mathrm{T}$ cells, the $\mathrm{T}$ cells exhibited both the green fluorescence of GFP and the red fluorescence of PE (Fig. 7B). These results confirmed the uptake of the GFP complex by $\mathrm{T}$ cells on the tumor cell surface, and the phenomenon is more obvious when $\mathrm{T}$ cells were cultured with B16/CD80$\mathrm{K}^{\mathrm{b}}$-GFP cells (Fig. 7C and D). These figures show clearly that $\mathrm{T}$ cells take up the GFP green fluorescent complex. It is interesting to observe the phenomenon of immune synapses formed by the interaction of the tumor cells with specific $\mathrm{T}$ cells, as shown in Fig. 7D. Thus, these results showed that the expression of costimulatory molecule CD80 with $\mathrm{K}^{\mathrm{b}}$, an MHC class I molecule, on the surface of tumor cells can enhance the reaction between $\mathrm{T}$ cells and tumor cells, and increase the uptake of the antigen peptide-MHC class I-GFP complex.

\section{Discussion}

$\mathrm{T}$ cell-mediated cellular immunity is the main anti-tumor resource of the organism. Optimal T-cell activation requires two distinct signals. Recently, the cytokine IL-12 has received much attention in the activation of $\mathrm{T}$ cells and exciting the immunity response of the organism, and has even been considered to be a third signal. IL-12 is a potent inducer of $\gamma$ interferon production by natural killer cells and T-helper lymphocytes. It plays a crucial role in the early induction of immune responses by triggering the differentiation of T-helper lymphocytes towards the Th1 subtype (16).

When IL-12 is offered alone to stimulate the tumor cell HepG2, the killing effect of CTL is not obviously strengthened, although it is when co-transfected with CD80. This indicates that the microenvironment of cytokines is an important link to determine the differentiation of $\mathrm{T}$ cells and the subsequent characteristics of the immune response (17). Some studies showed that the expression of CD80 contributes to the activation of $\mathrm{T}$ cells, but it does not cause the production of Th1 cells, suggesting that it may be some factor produced by the tumor cells that suppresses the production of Th1. That is to say, we can co-transfect CD80 and some cytokines to stabilize the cooperation of the microenvironment of $\mathrm{T}$ cells in the antitumor immunity responses.

The search for a tumor antigen peptide has become a focus of the present tumor research field. The tumor antigen peptide is presented to the cell surface and recognized by the corresponding $\mathrm{T}$ cell receptor after combining with the MHC molecule, thus activating the cytotoxicity of the T lymphocyte, making the organism produce a specific anti-tumor immunity response. Therefore, they have the potential for wide application in fields such as tumor immunity inoculation and immunization therapy. Because there are few known tumor antigen peptides, and we have not found clear tumor antigens to most clinical tumors, the search for tumor antigen peptides has become urgent.

Several methods have been used to identify antigen CTL epitopes (18-20). If the amino acid sequence of a protein antigen is known, overlapping peptides of 8-10 amino acid residues can be synthesized as the target. This method has been used to identify a number of CTL epitopes of virus proteins; CTL epitopes can be found by searching the binding sequence of $\mathrm{MHC}$ and determining the affinity of the potential antigen peptide with the MHC molecule; the majority of 

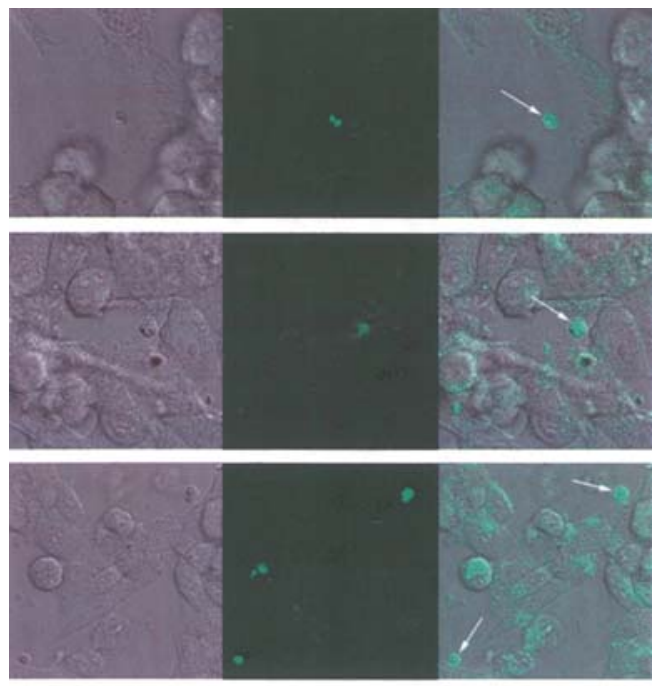

(A)
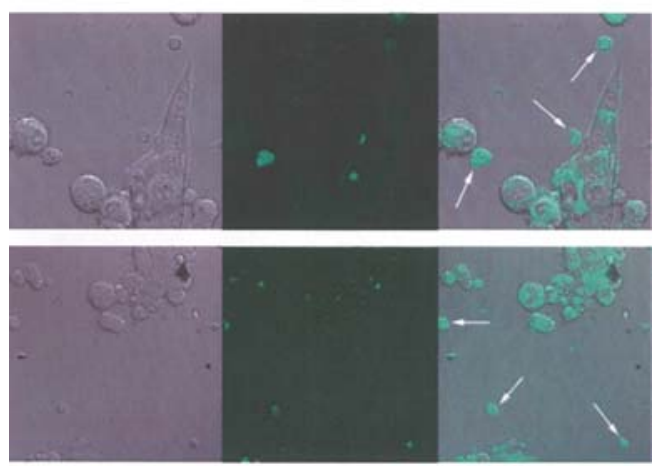

(B)
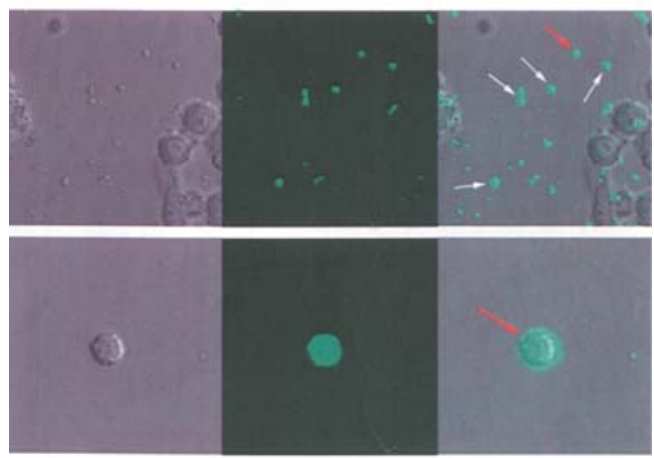

(C)

Figure 6. Observation of the uptake of the antigen peptide-MHC class I-GFP complex by $\mathrm{T}$ cells using laser scanning confocal fluorescence microscopy after gene-modified B16 cells and specific T cells were cocultured for $1 \mathrm{~h}$. (A) B16/K $\mathrm{K}^{\mathrm{b}}$-GFP cells were co-cultured with T cells. (B) and (C) B16/CD80$\mathrm{K}^{\mathrm{b}}$-GFP cells were co-cultured with $\mathrm{T}$ cells.

human tumor antigens now known have been identified by the transfection of genomic DNA or cDNA libraries into cells expressing the appropriate MHC molecule, followed by the identification of transfectants using cytokine release or lysis by human $\mathrm{T}$ cells with specific anti-tumor reactivity. These methods are selected directly from the perspective of finding antigenic peptides, the drawback is their poor specificity and large workload, just like looking for a needle in a haystack.

With elucidation of the recognition mechanism of $\mathrm{T}$ cells, the study of the recognition of $\mathrm{T}$ cells for tumor antigen has increased (21-25). A specific CTL clone can be induced in vitro

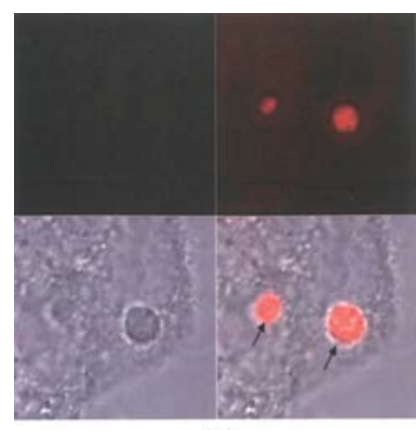

(A)

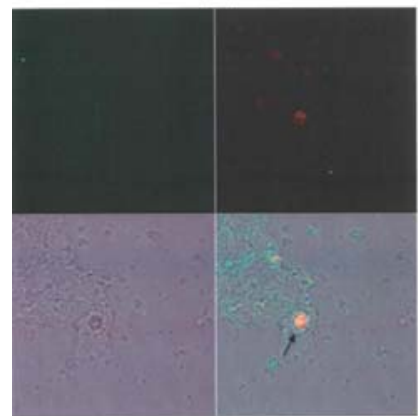

(B)

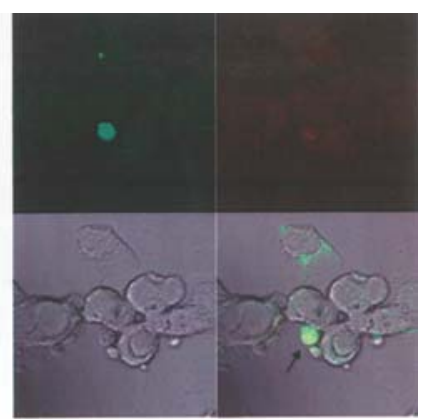

(C)

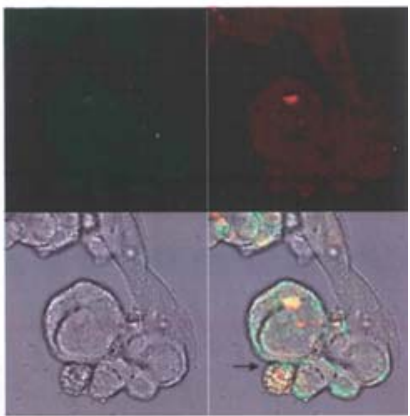

(D)
Figure 7. Dual-channel fluorescence analysis of the uptake of the antigen peptide-MHC class-GFP complex by T cells. B16 cells, B16/K $\mathrm{K}^{\mathrm{b}}-\mathrm{GFP}$ cells and B16/CD80-K ${ }^{\mathrm{b}}$-GFP cells were co-cultured with $\mathrm{T}$ cells at $37^{\circ} \mathrm{C}$ for $1 \mathrm{~h}$. Then T cells were tagged with PE-anti-mouse TCR antibody individually at $37^{\circ} \mathrm{C}$ for $1 \mathrm{~h}$. When cells were fixed, they were excited at a wavelength of $488 \mathrm{~nm}$. We observed green fluorescence at $512 \mathrm{~nm}$ and red fluorescence at $570 \mathrm{~nm}$. (A) B16 cells were co-cultured with $\mathrm{T}$ cells. (B) B16/K $\mathrm{K}^{\mathrm{b}}$-GFP cells were co-cultured with $\mathrm{T}$ cells. (C) and (D) B16/CD80-K ${ }^{\mathrm{b}}-\mathrm{GFP}$ cells were co-cultured with $\mathrm{T}$ cells.

using a tumor antigen peptide; it has become a powerful tool for finding and identifying tumor antigen peptides, and could be called a specific cell probe. Therefore, the reverse immunology technique has been used to identify candidate proteins. Using in vitro sensitization techniques, $\mathrm{T}$ cells against candidate antigens have been generated successfully. If these specific $\mathrm{T}$ cells can also recognize the intact tumor cells, such proteins are considered to be tumor antigen proteins. Therefore, peptides eluted selectively from the surface of tumor cells were exposed to the antigen-presenting cells to test the responses of the anti-tumor lymphocyte, and many tumor antigens recognized by $\mathrm{CD} 8^{+}$cells have been confirmed in this way (26).

Through the recognition and uptake of specific $\mathrm{T}$ cells in vitro, we used weak acid elution $(27,28)$ to acquire specific tumor antigen peptides based more directly on the phenomenon of TCR-mediated-endocytosis (29), using tumor antigen processing and presentation by MHC class I molecules. Because MHC class I molecules are expressed by tumor cells at a much lower level than the professional antigen-presenting cells, the proliferation of $\mathrm{T}$ lymphocyte cytotoxicity could not occur during the effector phase of the anti-tumor immune response, and the tumor escapes from the immune response. Recent studies have shown that many costimulatory molecules, in addition to their essential role in the development of the antigen-specific humoral response, appear to facilitate T-cell activation in response to low-affinity or low-abundance antigens by lowering the threshold required for activation and 
promoting the survival of activated $\mathrm{T}$ cells when the antigen concentration is not high, which helps to produce anti-tumor effector cells more effectively $(30,31)$. Therefore, co-expression of the tumor cell costimulatory molecule CD80 was used to observe whether it can enhance the response of $\mathrm{T}$ cells, overcome the immune escape of the tumor cells that increases the uptake of the tumor cell surface antigen peptide-MHC class I molecule-GFP complex and provide an experimental basis for the further isolation and identification of tumorassociated antigen peptides.

Approaches to increase the expression and function of the transgene are under study, including the possible use of lentiviral vectors, the use of more powerful promoters specific to $\mathrm{T}$ cells, the use of higher affinity TCRs that can mediate CD8-independent anti-tumor reactivity in CD4 cells, the further optimization of $\mathrm{T}$ cell transduction methods, and the production of higher titer good manufacturing practice-quality viruses. In this study, we constructed the co-expression vector of CD80 and GFP-tagged $\mathrm{K}^{\mathrm{b}}$ molecules to enhance the expression of costimulatory molecule CD80 and further provide the second stimulus signal needed for the activation of $\mathrm{T}$ cells to induce the effective anti-tumor immunity response. By using the recombinant GFP-tagged $\mathrm{K}^{\mathrm{b}}$ molecule, we observed TCR-mediated endocytosis of the antigen peptide-MHC class I complex through transfer of GFP protein between cells. The results show that little uptake of the antigen peptide-MHC class I-GFP complex was observed from the co-culturing of B16/K $\mathrm{K}^{\mathrm{b}}-\mathrm{GFP}$ and $\mathrm{T}$ cells, while the evident and intense uptake of antigen by specific $\mathrm{T}$ cells was seen for the B16/CD80-K $\mathrm{K}^{\mathrm{b}}$ GFP and $\mathrm{T}$ cells. These results show that co-expression of CD80 molecules with $\mathrm{K}^{\mathrm{b}}$, an MHC class I molecule, on the surface of tumor cells B16, can enhance the response of specific T cells.

In addition, after the recognition by $\mathrm{T}$ cells of the antigen peptide-MHC class I-GFP complex for $1 \mathrm{~h}$, we found that strong green fluorescence gathered mainly at the surface of $\mathrm{T}$ cells that had taken in the GFP-containing complex, over almost the entire cell membrane, and these are different from the results reported by Huang et al (29), who showed that $\mathrm{L}^{\mathrm{d}}$-GFP molecule on the target cell surface can be internalized by $\mathrm{T}$ cells when $\mathrm{T}$ cells recognize the complex for only $30 \mathrm{~min}$ and the green fluorescent area was found in $\mathrm{T}$ cells. An explanation for this difference may be the fact that in our research $\mathrm{T}$ cells were immunized in vivo and separated, and their recognition response to tumor cells was stronger than the response of $2 \mathrm{C} \mathrm{T}$ cells plus peptide QL9 to the target cells. Because, in our study, specific T cells may take up almost all of the antigen peptide complex presented by the MHC class I molecule, including known and unknown antigen peptide, and specific $\mathrm{T}$ cells might not be able to ingest all of these at once. This seems to provide a new opportunity for us to elute specific antigen peptides from $\mathrm{T}$ cells directly, and would pave the way for further studies with the aim of finding new methods to discover and test novel tumor-specific antigen peptides.

\section{Acknowledgements}

This study was supported by the National Key Program for Basic Research of China (2004CB518804) and the Science and Technology Commission of Shanghai (04JC14041).

\section{References}

1. Abken H, Hombach A, Heuser C, Kronfeld K and Seliger B: Tuning tumor-specific T-cell activation: a matter of costimulation? Trends Immunol 23: 240-245, 2002.

2. Chen L: Immunological ignorance of silent antigens as an explanation of tumor evasion. Immunol Today 19: 27-30, 1998.

3. Melief C: T-cell immunity against tumors, a delicate balancing act involving dendritic cells. Pathologie 49: 498-499, 2001.

4. Miyahira Y, Katae M, Kobayashi S, et al: Critical contribution of CD28-CD80/CD86 costimulatory pathway to protection from Trypanosoma cruzi infection. Infect Immun 71: 3131-3137, 2003.

5. Lang S, Atarashi Y, Nishioka Y, Stanson J, Meidenbauer N and Whiteside TL: B7.1 on human carcinomas: costimulation of $\mathrm{T}$ cells and enhanced tumor-induced T-cell death. Cell Immunol 201: 132-143, 2000 .

6. Zheng Y, Manzotti CN, Liu M, Burke F, Mead KI and Sansom DM: CD86 and CD80 differentially modulate the suppressive function of human regulatory T cells. J Immunol 172: 2778-2784, 2004.

7. Zuberek K, Ling V, Wu P, Ma HL, Leonard JP, Collins M and Dunussi-Joannopoulos K: Comparable in vivo efficacy of CD28/B7, ICOS/GL50, and ICOS/GL50B costimulatory pathways in murine tumor models: IFNgamma-dependent enhancement of CTL priming, effector functions, and tumor specific memory CTL. Cell Immunol 225: 53-63, 2003.

8. Van Gool SW, Vandenberghe P, De Boer M and Ceuppens JL: CD80, CD86 and CD40 provide accessory signals in a multiplestep T-cell activation model. Immunol Rev 153: 47-83, 1996.

9. Chung SW, Cohen EP and Kim TS: Generation of tumor-specific cytotoxic T lymphocyte and prolongation of the survival of tumorbearing mice using interleukin-18-secreting fibroblasts loaded with an epitope peptide. Vaccine 22: 2547-2557, 2004.

10. Dranoff $\mathrm{G}$ and Mulligan RC: Gene transfer as cancer therapy. Adv Immunol 58: 417-454, 1995.

11. Kim TS, Chung SW and Hwang SY: Augmentation of antitumor immunity by genetically engineered fibroblast cells to express both B7.1 and interleukin-7. Vaccine 18: 2886-2894, 2000.

12. Van Seventer GA, Newman W, Shimizu Y, et al: Analysis of T cell stimulation by superantigen plus major histocompatibility complex class II molecules or by CD3 monoclonal antibody: costimulation by purified adhesion ligands VCAM-1, ICAM-1, but not ELAM-1. J Exp Med 174: 901-913, 1991

13. Weaver CT and Unanue ER: The costimulatory function of antigen-presenting cells. Immunol Today 11: 49-55, 1990.

14. Sherritt M, Cooper L, Moss DJ, Kienzle N, Altman J and Khanna R: Immunization with tumor-associated epitopes fused to an endoplasmic reticulum translocation signal sequence affords protection against tumors with down-regulated expression of MHC and peptide transporters. Int Immunol 13: 265-271, 2001.

15. Chen L, McGowan P, Ashe S, Johnston J, Li Y, Hellstrom I and Hellstrom KE: Tumor immunogenicity determines the effect of B7 costimulation on T cell-mediated tumor immunity. J Exp Med 179: 523-532, 1994.

16. Langowski JL, Zhang X, Wu L, et al: IL-23 promotes tumour incidence and growth. Nature 442: 461-465, 2006.

17. Coutelier JP, van Broeck J and Wolf SF: Interleukin-12 gene expression after viral infection in the mouse. J Virol 69: 1955-1958, 1995

18. Coulie PG, Karanikas V, Colau D, et al: A monoclonal cytolytic T-lymphocyte response observed in a melanoma patient vaccinated with a tumor-specific antigenic peptide encoded by gene MAGE-3. Proc Natl Acad Sci USA 98: 10290-10295, 2001.

19. Schultze JL and Vonderheide RH: From cancer genomics to cancer immunotherapy: toward second-generation tumor antigens. Trends Immunol 22: 516-523, 2001

20. Smith ES, Mandokhot A, Evans EE, Mueller L, Borrello MA, Sahasrabudhe DM and Zauderer M: Lethality-based selection of recombinant genes in mammalian cells: application to identifying tumor antigens. Nat Med 7: 967-972, 2001.

21. Den Haan JM and Bevan MJ: Antigen presentation to $\mathrm{CD}^{+} \mathrm{T}$ cells: cross-priming in infectious diseases. Curr Opin Immunol 13: 437-441, 2001.

22. Pinilla C, Martin R, Gran B, Appel JR, Boggiano C, Wilson DB and Houghten RA: Exploring immunological specificity using synthetic peptide combinatorial libraries. Curr Opin Immunol 11: 193-202, 1999. 
23. Wang RF: The role of MHC class II-restricted tumor antigens and $\mathrm{CD} 4^{+} \mathrm{T}$ cells in antitumor immunity. Trends Immunol 22 : 269-276, 2001.

24. Watts C: Antigen processing in the endocytic compartment. Curr Opin Immunol 13: 26-31, 2001.

25. Yewdell JW and Bennink JR: Cut and trim: generating MHC class I peptide ligands. Curr Opin Immunol 13: 13-18, 2001.

26. Rosenberg SA: A new era for cancer immunotherapy based on the genes that encode cancer antigens. Immunity 10: 281-287, 1999.

27. Ramachandran S, Jaramillo A, Xu XC, McKane BW, Chapman WC and Mohanakumar T: Human immune responses to porcine endogenous retrovirus-derived peptides presented naturally in the context of porcine and human major histocompatibility complex class I molecules: implications in xenotransplantation of porcine organs. Transplantation 77: 1580-1588, 2004.
28. Storkus WJ, Zeh HJ III, Salter RD and Lotze MT: Identification of T-cell epitopes: rapid isolation of class I-presented peptides from viable cells by mild acid elution. J Immunother 14: 94-103, 1993.

29. Huang JF, Yang Y, Sepulveda H, et al: TCR-mediated internalization of peptide-MHC complexes acquired by $\mathrm{T}$ cells. Science 286: 952-954, 1999.

30. Giuntoli RL II, Lu J, Kobayashi H, Kennedy R and Celis E: Direct costimulation of tumor-reactive CTL by helper T cells potentiate their proliferation, survival, and effector function. Clin Cancer Res 8: 922-931, 2002.

31. Michel F, Attal-Bonnefoy G, Mangino G, Mise-Omata S and Acuto O: CD28 as a molecular amplifier extending TCR ligation and signaling capabilities. Immunity 15: 935-945, 2001. 